\title{
RANCANG BANGUN SISTEM PENGEREMAN MESIN GERINDA DUDUK
}

\author{
Sirajuddin $^{1}$, Rustang $^{2}$ \\ 1,2 Jurusan Teknik Mesin, Politeknik Negeri Ujung Pandang, Makassar 90245, Indonesia \\ Email; sirajuddin@poliupg.ac.id ${ }^{1}$, rustang@poliupg.ac.id ${ }^{2}$
}

\begin{abstract}
The purpose of this research is to design and build several braking systems on sitting grinding machine. then the specific purpose is to design and create a dynamic braking system on a grinding machine sitting in a mechanical workshop at the Ujung Pandang State Polytechnic Mechanical Engineering. This methodology includes system design, preparation of materials and tools, and for assembly fabrication of the system and obtaining of the results. With the result that obtained a dynamic braking installation on grinding machine. The achieved are by supplying dc voltage to the stator coil to the grinding machine motor when the grinding machine is off with a variation dc voltage of $30 \mathrm{v}, 50 \mathrm{v}, 70 \mathrm{v}, 90 \mathrm{v}$, and $110 \mathrm{v}$, and with variations diameter of the grinding stone $16 \mathrm{~cm}, 18, \mathrm{~cm}$ and $20 \mathrm{~cm}$, the fastest braking result is the highest voltage 110 volts $\mathrm{dc}$ with the smallest diameter of the grinding stone $16 \mathrm{~cm}$ is 3.41 seconds, so as can be concluded that the greater the DC voltage supplied and the smaller the grinding stone from the grinding machine, the faster also the results of braking. The realization of the dynamic braking system installation, the grinding machine sits in the mechanical workshop of the Ujung Pandang State Polytechnic Mechanical Engineering course can certainly prevent the user in braking errors, improve work safety, comfort and can be used for students learning.
\end{abstract}

Keywords: Braking, Dynamic Braking, Braking Grinding Machine

\begin{abstract}
Abstrak: Tujuan jangka panjang penelitian ini adalah merancang dan membuat beberapa sistem pengereman pada mesin gerinda duduk. Sedangkan tujuan khususnya adalah merancang dan membuat sistem pengereman dinamik pada mesin gerinda duduk pada bengkel mekanik Jurusan Teknik Mesin Politeknik Negeri Ujung Pandang. Metodologi ini mencakup perancangan sistem, persiapan bahan dan alat, perakitan dan pembuatan sistem serta pengambilan hasil. Sehingga terbentuklah sebuah instalasi pengereman dinamik pada mesin gerinda duduk. Hasil yang dicapai adalah dengan mensuplai tegangan dc ke dalam kumparan stator motor mesin gerinda pada saat mesin gerinda dioffkan dengan variasi tegangan dc sebesar $30 \mathrm{v}, 50 \mathrm{v}, 70 \mathrm{v}, 90 \mathrm{v}$, dan $110 \mathrm{v}$ dengan variasi diameter batu gerinda $16 \mathrm{~cm}, 18, \mathrm{~cm}$ dan $20 \mathrm{~cm}$, diperoleh hasil pengereman tercepat adalah tegangan yang tertinggi 110 volt de dengan diameter batu gerinda yang terkecil $16 \mathrm{~cm}$ yaitu 3.41 detik, sehingga dapat diisimpullkan bahwa semakin besar tegangan DC yang disuplai dan semakin kecil batu gerinda dari mesin gerinda tersebut maka semakin cepat pula hasil pengeremannya. Dengan terwujudnya instalasi sistem pengereman dinamik mesin gerinda duduk pada bengkel mekanik Jurusan Teknik mesin Politeknik Negeri Ujung Pandang tentunya dapat mencegah praktikan dalam kesalahan pengereman, meningkatkan keamanan dan kenyamanan kerja serta dapat dijadikan sebagai pembelajaran buat mahasiswa.
\end{abstract}

Kata kunci : Pengereman, Pengereman Dinamik, Pengereman Mesin Gerinda

\section{PENDAHULUAN}

a. Latar belakang

Mesin gerinda dipergunakan pada semua jenis perbengkelan, demikian halnya pada bengkel mekanik Jurusan Teknik Mesin Politeknik Negeri Ujung Pandang. Berkaitan dengan pengasahan peralatan maka diadakanlah beberapa jenis mesin gerinda salahsatunya mesin gerinda duduk untuk mengasah pahat dan membuat pahat bubut.

Salahsatu bagian dari mesin gerinda duduk adalah motor. Jenis motor yang digunakan oleh mesin gerinda duduk adalah jenis motor induksi tiga phasa rotor sangkar. Pada penggunaannya, motor induksi sering dibutuhkan proses menghentikan putaran motor dengan cepat. Sementara kondisi mesin gerinda duduk pada bengkel mekanik jurusan teknik mesin politeknik negeri ujung pandang saat ini belum mempunyai sistem pengereman untuk mesin gerinda duduk, sehingga kadangkala mahasiswa/praktikan apabila selesai bekerja/memutuskan arus ke motor dikarenakan 
batu gerinda masih tetap berputar dan menimbulkan getaran serta suara bising maka mereka menghentikan putaran batu gerinda dengan cara yang keliru yaitu dengan menahan batu gerinda tersebut dengan besi atau benda kerja mereka. Hal ini sangat berbahaya buat keselamatan kerja praktikan, benda kerja serta mesin gerinda tersebut.

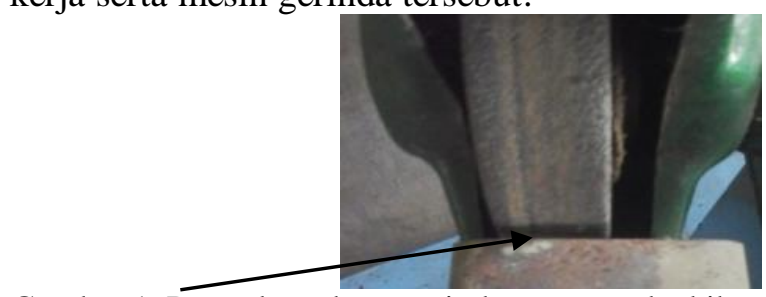

Gambar 1. Permukaan batu gerinda yang rusak akibat pengereman yang salah

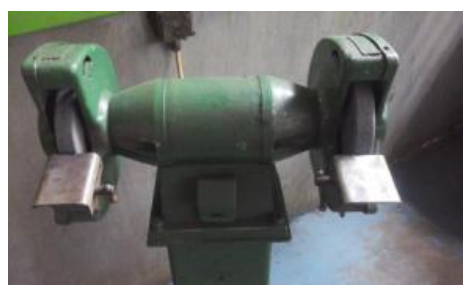

Gambar 2. Mesin gerinda duduk yang menjadi objek penelitian

Beberapa penelitian yang telah dilakukan oleh para peneliti sebelumnya tentang pengereman motor induksi tiga phasa seperti Rancang Bangun Pengereman Dinamik Motor Induksi Tiga Fasa Dengan Pengaturan Arus Dc Dan Output Rotor oleh Andy Guntur [1] , Pengaturan Pengereman Dinamik Motor Induksi Tiga Fasa Berbasis Smartphone Android Dan Simulasi Matlab Oleh Firmansyah Deny[3], Pemodelan Dan Simulasi Pengereman Dinamik Motor Induksi Tiga Fasa oleh Nizar Rama, dkk [4].

\section{b. Momen Inersia.}

Momen inersia adalah kecenderungan suatu benda untuk mempertahankan keadaan putarnya baik tetap diam atau tetap bergerak memutar. Jika momen inersia besar maka benda akan sulit untuk melakukan perputaran dari keadaan diam dan semakin sulit berhenti ketika dalam keadaan berotasi, itu sebabnya momen inersia juga disebut sebagai momen rotasi [6]. Setiap benda tegar bergerak melingkar di masing-masing titik partikel geraknya, hal ini merupakan acuan tertentu yang dapat ditentukan dengan momen inersia [7].

Untuk benda-benda yang bentuknya teratur dan telah diketahui secara umum, rumus momen inersianya dapat dilihat pada tabel dibawah ini [8] :

Tabel 1. Rumus momen inersia berbagai benda

\begin{tabular}{|c|c|c|c|}
\hline Benda & Sumbu Putar & Rumus Momen Inersia \\
\hline Batang silinder & $\begin{array}{c}\text { Tepat melalui pusat dan } \\
\text { tegak lurus batang }\end{array}$ & $I=\frac{1}{12} m^{2}$ \\
\hline Silinder pejal & Melalui titik pusat silinder & $I=\frac{1}{2} m R^{2}$ \\
Bola pejal & Tepat melalui titik pusat & $I=\frac{2}{3} m R^{2}$ \\
\hline
\end{tabular}




\section{c. Motor Induksi}

Motor induksi merupakan motor yang paling umum digunakan pada berbagai peralatan industri. Popularitasnya karena rancangannya yang sederhana, murah dan mudah didapat, dan dapat langsung disambungkan ke sumber daya AC. Ada dua jenis rotor motor induksi, yaitu rotor belitan (wound rotor) dan rotor sangkar (squirrel-cage rotor)..

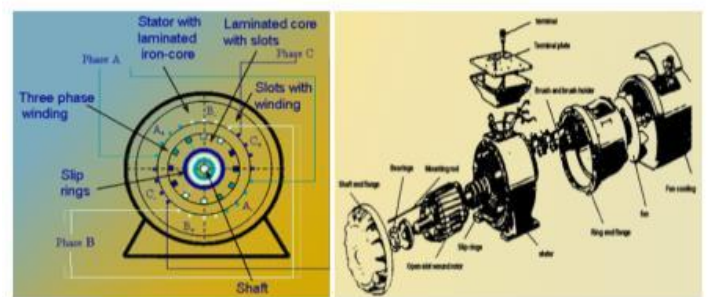

(a)

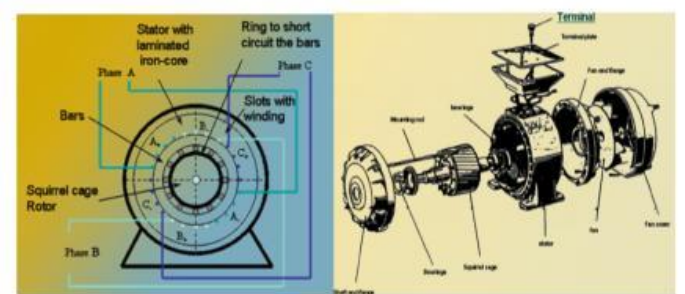

(b)

Gambar 2. (a) Rotor Belitan (b) Rotor Sangkar [4]

\section{d. Pengereman}

Pengereman adalah sebuah sistem untuk mengurangi atau memperlambat dan menghentikan laju kendaraan atau motor. Adapun khuusus pengereman pada motor induksi adalah pengereman regeneratif, flugging dan dinamik.[1], [2], [4].

a. Pengereman regenerative yaitu metode dengan mengandalkan energi yang dihasilkan motor pada saat motor tersebut digerakkan beban.

b. Pengereman Secara Plugging yaitu dengan cara membalikkan arah gerak motor.

Penelitian dengan menggunakan jenis pengereman ini pernah dilakukan oleh Rejani Erwanda tahun 2016 dengan judul Rancang Bangun Prototipe Pengendali Kecepatan Motor Induksi 3 Fasa Dengan Pengaturan Tegangan Berbasis Mikrokontroler Arduino Dan Android Smartphone dengan mengatakan bahwa pengereman plugging pada motor induksi dilakukan dengan membalik urutan fasa pada motor, yaitu dengan merubah koneksi dari kedua fasa yang berasal dari sumber menuju ke stator (gambar dibawah ini). Ketika kontaktor F tertutup, motor akan beroperasi pada kurva torsi kecepatan F, dan ketika kontaktor R tertutup, motor akan beroperasi dengan kurva R. Dari rata rata kurva $\mathrm{R}$, diekspektasikan torsi pengereman relatif mendekati $110 \%$ untuk mencapai kondisi steady state

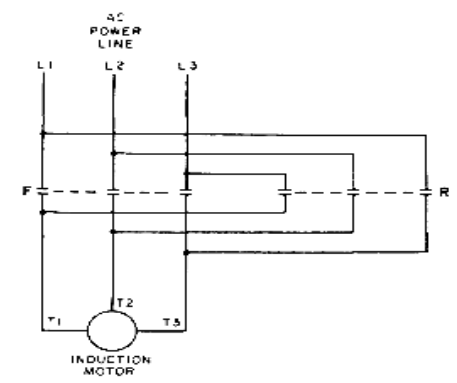

Gambar 3. Induction Motor Plugging Wiring [2]

\section{c. Pengereman Dinamik}

Pengereman dinamik adalah metode pengereman motor induksi dengan cara menginjeksikan arus searah (dc) pada stator sehingga akan mengembangkan medan stasioner untuk menurunkan tegangan pada rotor. Karena rotor dalam keadaan hubung singkat maka akan timbul medan magnet yang berputar sama dengan kecepatan rotor namun dengan arah yang berlawanan. Interaksi medan resultan dengan gaya gerak magnet pada rotor menimbulkan torsi yang berlawanan dengan torsi motor sehingga pengereman dapat terjadi, [3], [5].

Untuk mencapai torsi pengereman yang tinggi, belitan pada motor harus diberi eksitasi penuh. Intensitas pengereman pada eksitasi konstan tergantung dari arus yang diberikan pada kumparan 
jangkar dan dengan menentukan tahanan $(\mathrm{Rb})$. Untuk menghitung besarnya tahanan pada pengereman dinamik dapat dilihat dari persamaan dasar penurunan tegangan pada kumparan jangkar berikut ini: [3]

$\mathrm{E}=\mathrm{I}(\mathrm{Rarm}+\mathrm{Rb})$

Tahanan untuk pengereman dinamik adalah sebagai berikut :

$$
\mathrm{Rb}=\frac{\mathrm{E}}{\mathrm{I}}-\text { Rarm }
$$

Dimana :

E : Tegangan pada saat pengereman dinamik $(\mathrm{V})$

I : Arus pada saat pengereman dinamik (A)

Rarm : Tahanan jangkar motor $(\Omega)$

$\mathrm{Rb}$ : Tahanan pengereman $(\Omega)$

Rangkaian pengereman dinamik motor induksi tiga fasa dapat dilihat dari gambar berikut ini :

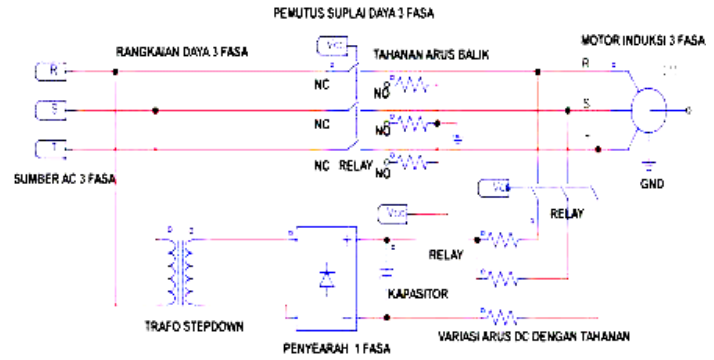

(a)

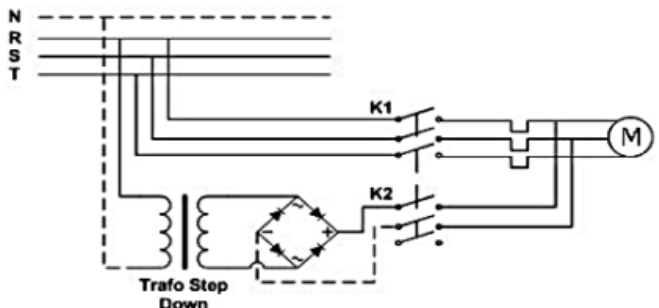

(b)

Gambar 4. (a) Pengereman Dinamik (b) Pengereman Dinamik [5]

\section{METODE PENELITIAN}

Penelitian dilakukan di bengkel Mekanik Jurusan Teknik Mesin, karena sebagian besar mesin dan peralatan serta alat ukur tersedia dengan lengkap yang menunjang penelitian yang dilakukan. Sedangkan waktu pelaksanaan penelitian dilakukan pada bulan April - Oktober 2019. Adapun tahapan penelitian sebagai berikut:

1. Observasi lokasi dan objek penelitian

Objek penelitian adalah mesin gerinda dengan lokasi paling dekat dengan panel surya utama.

2. Menyiapkan alat dan bahan

Alat yang digunakan yaitu travo variabel, tang, obeng, test pen, solder, multitester analog, stop watch. Sedangkan bahan yang digunakan diantaranya yaitu travo CT 5A, timer Omron h3ba 8 kaki, ampermeter, dan voltmeter analog, kontaktor, MCB, dioda, panel listrik, push button 'on', push button 'off', dan kabel instalasi. 

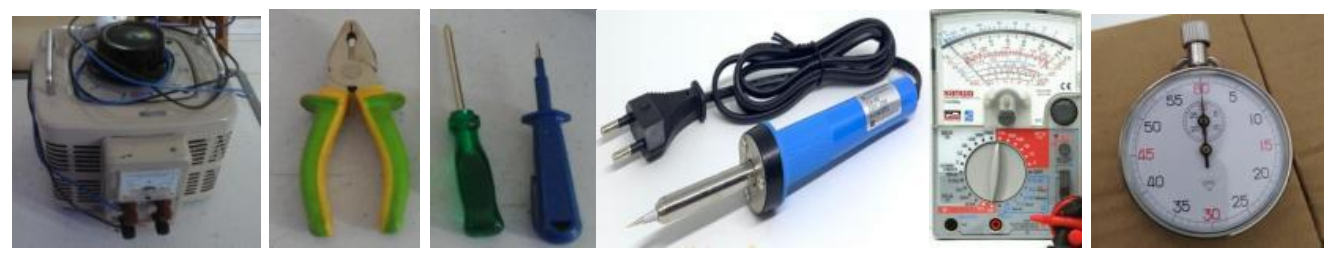

(a)
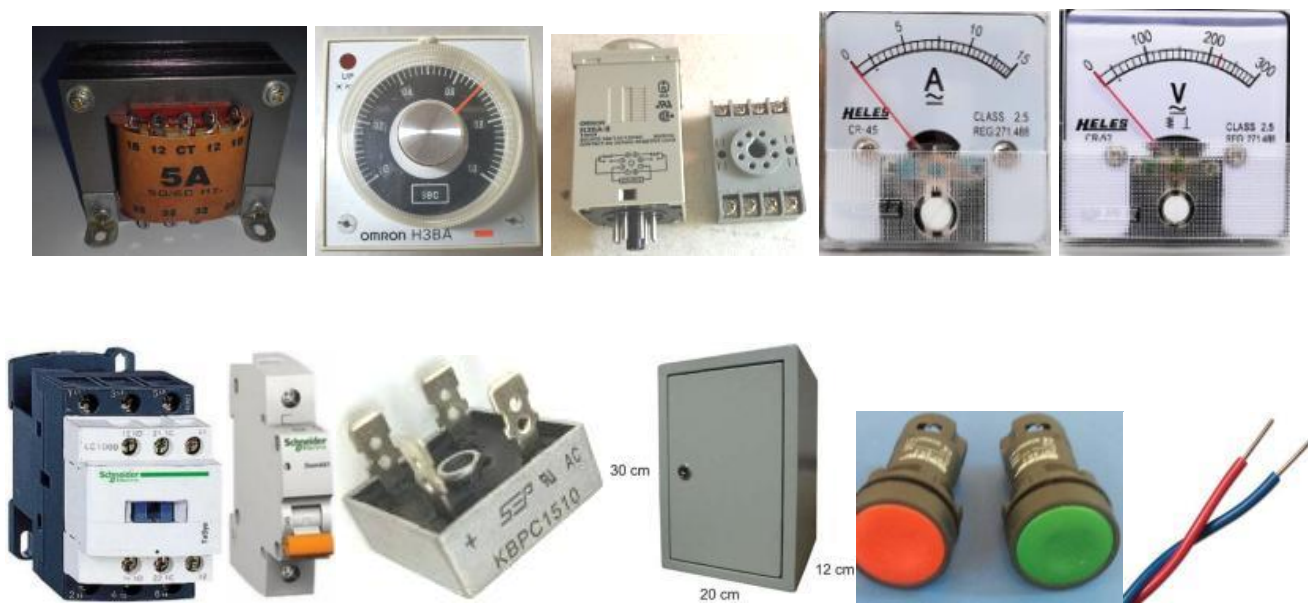

(b)

Gambar 5. (a) alat dan (b) bahan yang dibutuhkan

3. Perakitan

\section{A. Metode Perancangan}

1. Review paper/jurnal, yaitu mencari referensi terkait motor induksi tiga phasa, mesin gerinda, sistem pengereman, penyearah satu pasa dan relai.

2. Perancangan sistem, yaitu merancang sistem pengereman dinamik pada mesin gerinda duduk agar dapat mempercepat berhentinya sisa putaran saat mesin di matikan, sebagai berikut:

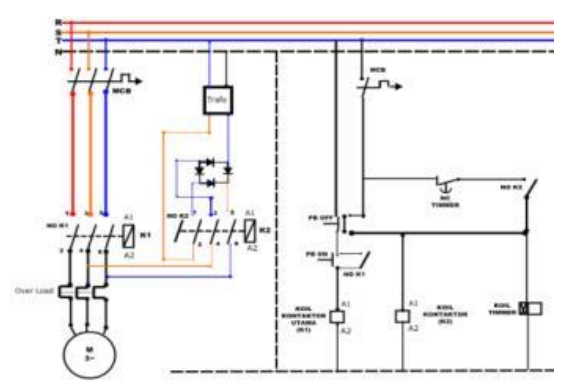

Gambar 6. Rancangan rangkaian sistim pengereman dinamik

\section{B. Metode Pembuatan dan Perakitan}

1. Persiapan alat yaitu observasi dibengkel mekanik untuk memilih mesin gerinda yang akan dipasangi instalasi lalu mempersiapkan seluruh peralatan yang akan digunakan.

2. Persiapan bahan yang akan digunakan dalam pembuatan instaasi sistem. 
3. Pembuatan/perakitan instalasi, yaitu merangkai semua komponen dan merakitnya sesuai rancangan kemudian menginstalnya dilokasi yang telah ditentukan sebelumnya.

\section{Metode Pengambilan Data}

1. Pengambilan data waktu yang diperlukan mesin gerinda untuk berhentinya sisa putaran tanpa menggunakan sistem pengereman pada tiga buah mesin gerinda yang batu gerindanya berbeda diameter yaitu diameter $16 \mathrm{~cm}, 18 \mathrm{~cm}$, dam $20 \mathrm{~cm}$.

Pengukuran waktu yang dibutuhkan untuk berhenti total mesin gerinda duduk dengan tidak menggunakan sistem pengereman pada mesin gerinda yang berbeda diameter batu gerindanya yaitu diameter $16 \mathrm{~cm}, 18 \mathrm{~cm}$, dan $20 \mathrm{~cm}$.

Tabel 2. Hasil pengukuran waktu berhenti tanpa pengereman

\begin{tabular}{|c|c|c|c|c|c|}
\hline No. & $\begin{array}{c}\text { Diameter } \\
\text { batu gerinda }(\mathrm{cm})\end{array}$ & $\begin{array}{c}\text { Putaran batu } \\
\text { gerinda }\end{array}$ & $\begin{array}{c}\text { Massa Batu } \\
\text { grinda }\end{array}$ & $\begin{array}{c}\text { Momen } \\
\text { inersia } 1 / 2 \mathrm{mR}^{2}\end{array}$ & $\begin{array}{c}\text { Waktu untuk berhenti } \\
\text { tanpa pengereman } \\
\text { (detik) }\end{array}$ \\
\hline 1 & 16 & $3000 \mathrm{rpm}$ & $0,95 \mathrm{~kg}$ & $30.4 \mathrm{~kg} \cdot \mathrm{m}^{2}$ & 23.45 \\
\hline 2 & 18 & $3000 \mathrm{rpm}$ & $1,1 \mathrm{~kg}$ & $44.5 \mathrm{~kg} \cdot \mathrm{m}^{2}$ & 48.46 \\
\hline 3 & 20 & $3000 \mathrm{rpm}$ & $1,6 \mathrm{~kg}$ & $80 \mathrm{~kg} \cdot \mathrm{m}^{2}$ & 106.39 \\
\hline
\end{tabular}

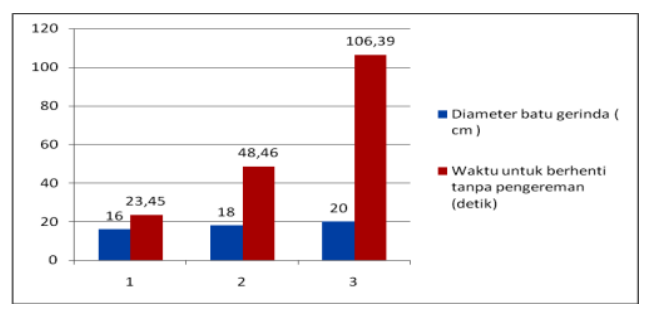

Gambar 7. Hasil pengukuran waktu berhenti tanpa pengereman

Hasil pengukuran diatas menunjukkan bahwa waktu yang dibutuhkan untuk berhenti total pada sebuah mesin gerinda duduk setelah dioffkan atau dimatikan tanpa pengereman adalah semakin besar batu gerinda pada mesin gerinda tersebut maka semakin besar putaran sisanya sehingga membutuhkan waktu yang lebih lama untuk berhenti.

2. Pengambilan data waktu yang diperlukan mesin gerinda untuk berhentinya sisa putaran dengan menggunakan sistem pengereman pada tiga buah mesin gerinda yang batu gerindanya berbeda diameter yaitu diameter $16 \mathrm{~cm}, 18 \mathrm{~cm}$, dam $20 \mathrm{~cm}$, dimana dilakukan dengan mensuplai tegangan DC yang berbeda yaitu $30 \mathrm{v}, 50 \mathrm{v}, 70 \mathrm{v}, 90 \mathrm{v}$, dan $110 \mathrm{v}$

Metode setting arus DC yang akan disuplay sebagai berikut:

1. Travo Variabel digunakan sebagai uji suplay arus untuk setiap sampel ukuran batu gerinda.

2. Mesin gerinda untuk batu gerinda ukluran diameter $20 \mathrm{~cm}$, di jalankan tanpa pengereman dan diukur waktu berhentinya. Selanjutnya disuplay arus arus DC saat di offkan dengan variasi arus $30 \mathrm{~V}, 50 \mathrm{~V}, 70 \mathrm{~V}, 90 \mathrm{~V}$, dan $110 \mathrm{~V}$ dan masing-masing diukur waktu yang dibutuhkan untuk berhenti menggunakan stopwatch.

3. Dilanjutkan dengan menggunakan batu gerinda yang ukluran diameter $18 \mathrm{~cm}$, di jalankan tanpa pengereman dan diukur waktu berhentinya. Selanjutnya disuplay arus arus DC saat 
di offkan dengan variasi arus $30 \mathrm{~V}, 50 \mathrm{~V}, 70 \mathrm{~V}, 90 \mathrm{~V}$, dan $110 \mathrm{~V}$ dan masing-masing diukur waktu yang dibutuhkan untuk berhenti menggunakan stopwatch.

4. Dilanjjutkan dengan menggunakan batu gerinda yang ukluran diameter $16 \mathrm{~cm}$, di jalankan tanpa pengereman dan diukur waktu berhentinya. Selanjutnya display arus arus DC saat di offkan dengan variasi arus $30 \mathrm{~V}, 50 \mathrm{~V}, 70 \mathrm{~V}, 90 \mathrm{~V}$, dan $110 \mathrm{~V}$ dan masing-masing diukur waktu yang dibutuhkan untuk berhenti menggunakan stopwatch.

5. Selanjutnya melakukan perakitan sistem berdasarkan hasil yang diperoleh diatas, lalu setting timer waktu yang dibutuhkan berhenti pada mesin gerinda dengan ukuran batu gerinda yang terpasang.

Cara pengoperasian alat pengereman yaitu sebagai berikut:

1. MCB 3 phasa dan 1 phasa harus pada posisi on

2. Tekan "PB On" untuk menjalankan mesin gerinda, pada posisi ini arus masuk ke koil kontaktor 1(utama) dan mengaktifkan kontaktor utama yang menuju beban sehingga beban beroperasi yaitu mesin gerinda (Kontaktor 1(utama) berada pada panel utama bengkel mesin).

3. Tekan "PB Off" untuk menghentikan mesin gerinda beroperasi (fungsi pengereman), pada posisi ini arus 3 phasa berhenti sedangkan arus 1 phasa masuk ke koil kontaktor 2 (pengereman) dan koil timer, koil tersebut mengaktifkan kontaktor 2 yang mensuplai arus DC dari travo sebesar yang telah disetting bersamaan dengan itu timer berfungsi selama waktu yang telah disetting sebelumnya untuk menghentikan suplai arus DC dari kontaktor 2 bila motor gerinda telah berhenti.

\section{HASIL DAN PEMBAHASAN}

Waktu yang dibutuhkan untuk berhenti total mesin gerinda duduk dengan menggunakan sistem pengereman dinamik pada mesin gerinda dengan suplai tegangan dc yang berbeda yaitu $30 \mathrm{v}, 50 \mathrm{v}, 70$ $\mathrm{v}, 90 \mathrm{v}$, dan $110 \mathrm{v}$ dengan diameter dan massa batu gerinda yang berbeda pula yaitu diameter $16 \mathrm{~cm}$ $(0,95 \mathrm{~kg}), 18 \mathrm{~cm}(1,1 \mathrm{~kg})$, dan $20 \mathrm{~cm}(1,6 \mathrm{~kg})$.

\section{a. Pengukuran pada mesin gerinda yang berdiameter $16 \mathrm{~cm}(0,95 \mathrm{~kg})$}

Tabel 3. Hasil pengukuran waktu pengereman dinamik untuk diameter batu gerinda $16 \mathrm{~cm}$ dengan variasi tegangan DC

\begin{tabular}{|c|c|c|}
\hline No. & $\begin{array}{c}\text { Tegangan DC } \\
\text { (volt) }\end{array}$ & Waktu untuk berhenti dengan pengereman dinamik (detik) \\
\hline 1 & 30 & 8.92 \\
\hline 2 & 50 & 7.03 \\
\hline 3 & 70 & 4.23 \\
\hline 4 & 90 & 3.95 \\
\hline 5 & 110 & 3.43 \\
\hline
\end{tabular}




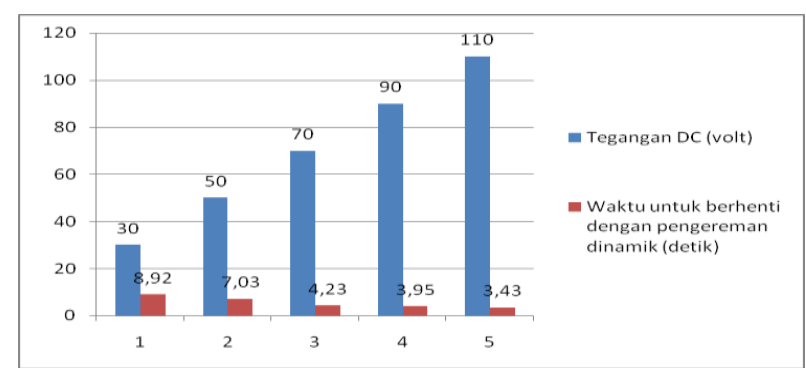

Gambar 8. Hasil pengukuran waktu pengereman dinamik untuk diameter batu gerinda $16 \mathrm{~cm}$ dengan variasi tegangan DC

Hasil pengukuran di atas menunjukkan bahwa pengukuran pengereman dinamik pada mesin gerinda yang berdiameter $16 \mathrm{~cm}$ dengan variasi tengangan adalah pengereman tercepat pada tegangan 110 DC yaitu 3.43 detik.

\section{b. Pengukuran pada mesin gerinda yang berdiameter $18 \mathrm{~cm}(1,1 \mathrm{~kg})$}

Tabel 4. Hasil pengukuran waktu pengereman dinamik untuk diameter batu gerinda $18 \mathrm{~cm}$ dengan variasi tegangan DC

\begin{tabular}{|c|c|c|}
\hline No. & Tegangan DC (volt) & $\begin{array}{c}\text { Waktu untuk berhenti dengan pengereman dinamik } \\
\text { (detik) }\end{array}$ \\
\hline 1 & 30 & 16.72 \\
\hline 2 & 50 & 11.12 \\
\hline 3 & 70 & 5.98 \\
\hline 4 & 90 & 4.33 \\
\hline 5 & 110 & 3.61 \\
\hline
\end{tabular}

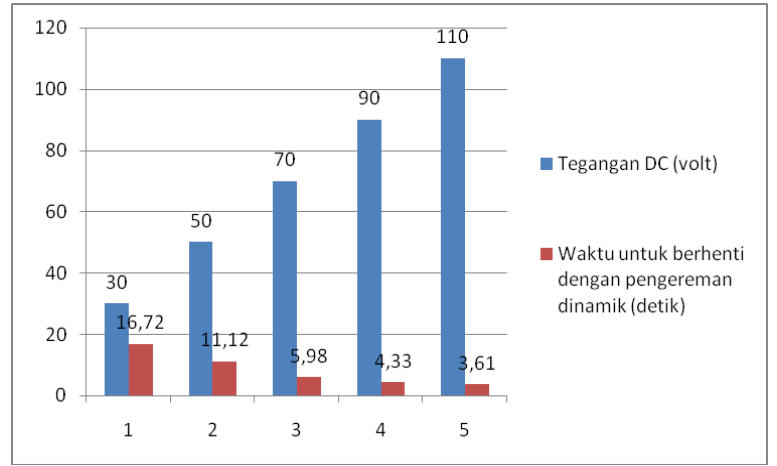

Gambar 9. Hasil pengukuran waktu pengereman dinamik untuk diameter batu gerinda $18 \mathrm{~cm}$ dengan variasi tegangan $\mathrm{DC}$

Hasil pengukuran diatas menunjukkan bahwa pengukuran pengereman dinamik pada mesin gerinda yang berdiameter $18 \mathrm{~cm}$ dengan variasi tengangan adalah pengereman tercepat pada tegangan 110 DC yaitu 3.61 detik.

\section{c. Pengukuran pada mesin gerinda yang berdiameter $20 \mathrm{~cm}(1,6 \mathrm{~kg})$}

Tabel 5. Hasil pengukuran waktu pengereman dinamik untuk diameter batu gerinda $20 \mathrm{~cm}$ dengan variasi tegangan DC

\begin{tabular}{|c|c|c|}
\hline No. & Tegangan DC (volt) & Waktu untuk berhenti dengan pengereman dinamik \\
(detik)
\end{tabular}




\begin{tabular}{|l|c|c|}
\hline 2 & 50 & 16.23 \\
\hline 3 & 70 & 10.01 \\
\hline 4 & 90 & 7.27 \\
\hline 5 & 110 & 6.03 \\
\hline
\end{tabular}

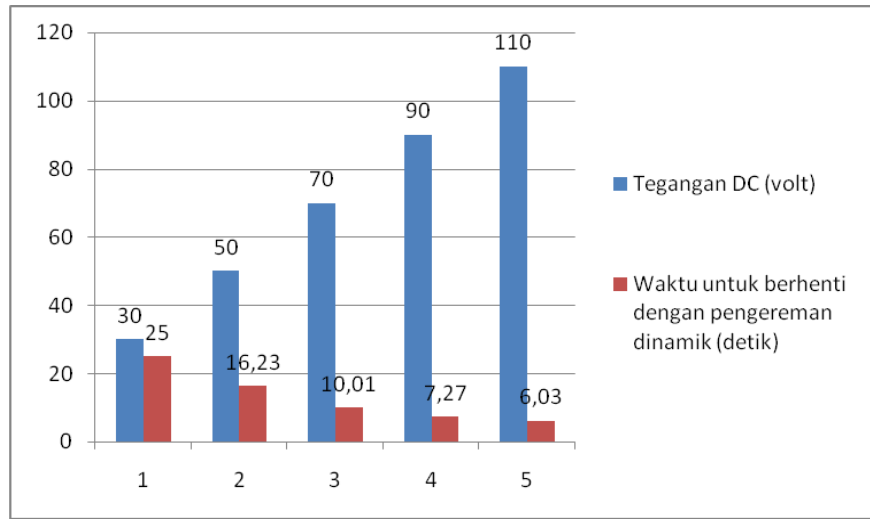

Gambar 10. Hasil pengukuran waktu pengereman dinamik untuk diameter batu gerinda $20 \mathrm{~cm}$ dengan variasi tegangan DC

Hasil pengukuran diatas menunjukkan bahwa pengukuran pengereman dinamik pada mesin gerinda yang berdiameter $20 \mathrm{~cm}$ dengan variasi tengangan adalah pengereman tercepat pada tegangan $110 \mathrm{v}$ DC yaitu 6,03 detik.

\section{KESIMPULAN}

Dari data hasil pengukuran dengan variasi ukuran diameter $16 \mathrm{~cm}, 18 \mathrm{~cm}$, dan $20 \mathrm{~cm}$ dengan suplai tegangan DC yang bervasiasi $30 \mathrm{v}, 50 \mathrm{v}, 70 \mathrm{v}, 90 \mathrm{v}$, dan $110 \mathrm{v}$, diperoleh pengereman tercepat pada mesin gerinda yang berdiameter $16 \mathrm{~cm}$ dengan tegangan $110 \mathrm{v}$ DC yaitu 3.43 detik. Dengan demikian diperoleh kesimpulan bahwa semakin kecil diameter batu gerinda dan semakin semakin besar suplai tegangan DC maka hasil pengeremannya semakin cepat.

\section{DAFTAR PUSTAKA}

[1] Andy Guntur, 2016,, Rancang Bangun Pengereman Dinamik Motor Induksi Tiga Fasa Dengan Pengaturan Arus Dc Dan Output Rotor, Departemen Teknik Elektro Fakultas Teknik Universitas Sumatera Utara Medan.

[2] Erwanda, Rejani., 2016. Rancang Bangun Prototipe Pengendali Kecepatan Motor Induksi 3 Fasa dengan Pengaturan Tegangan Berbasis Mikrokontroler Arduino dan Android Smartphone. Teknik Elektro. Universitas Lampung. Lampung.

[3] Firmansyah Denny, 2016, Pengaturan Pengereman Dinamik Motor Induksi Tiga Fasa Berbasis Smartphone Android Dan Simulasi Matlab, Fakultas Teknik Universitas Lampung Bandar Lampung.

[4] Nizar Rama dan Miduk Hiras T, 2015. Pemodelan Dan Simulasi Pengereman Dinamik Motor Induksi Tiga Fasa, Sekolah tinggi manajemen informatika dan computer IBBI, Medan.

[5] Prabowo, Andreas. 2013. Perancangan Dinamic Braking pada Motor Induksi Tiga Fasa Berbasis Mikrokontroler ATMEGA16. Jurusan Teknik Elektro. Universitas Pakuan Bogor. Bogor

[6] Rivia, N., 2016. Pembuatan Alat Ukur Momen Inersia Benda Digital Menggunakan Sensor Optocoupler. Pillar Of Physics , 8, 81-88.

[7] Sahala S., 2013. Penentuan Inersia Benda Tegar Dengan Bandul Fisis. PendidikaMatematika Dan IPA , 4 (2), 36-42

[8] https://www.studiobelajar.com/momen-inersia/ Mei 2019 